\title{
Renal colic, where is it headed? An observational study
}

\author{
Paolo Beltrami ${ }^{1}$, Andrea Guttilla ${ }^{1}$, Lorenzo Ruggera ${ }^{2}$, Patrizia Bernich ${ }^{3}$, Filiberto Zattoni ${ }^{1}$ \\ ${ }^{1}$ Urology Clinic, Department of Surgical, Oncological and Gastroenterological Sciences, University of Padova, Padova, Italy; \\ ${ }^{2}$ Department of Urology, S. Maria degli Angeli Hospital, Pordenone, Italy; \\ ${ }^{3}$ Department of Nephrology, University of Verona, Verona, Italy.
}

\begin{abstract}
Summary Aim: In the last thirty years, the treatment for renal and ureteral calculi has undergone profound variations. The objective of this study has been to evaluate the existence of parameters which can affect the spontaneous expulsion of a symptomatic ureteral stone in a reasonably brief period of time and to identify whether certain parameters such as sex, age, the location and dimension of the stone, the presence of dilation in the urinary tract together with the administered therapy, can be used for a correct clinical management of the patient.

Methods: In a period of 9 months, 486 cases of renal colic were registered at emergency department.

Results: The cases of renal colic due to ureteral calculus were $188(38.7 \%)$. The patients' charts, complete of all data and therefore, valid for this research, resulted to be 120 (64\%). In the presence of a symptomatic ureteral stone, the correct approach must first of all, focalize on the dimension of the calculus itself; less importance instead, is given to the location, as reported in other studies, the presence of hydroureteronephrosis, sex and the side.

Conclusion: In the cases when the pain symptoms cannot be solved by means of the administration of analgesics, it is then reasonable to take into consideration an immediate endourological treatment. If the pain symptoms are promptly solved, an attentive wait of 4 weeks should be considered reasonable in order to allow spontaneous expulsion of the calculus.
\end{abstract}

KEY WORDS: Renal colic; Emergency treatment; Stones; Ureteroscopy; SWL.

Submitted 25 April 2015; Accepted 8 september 2015

\section{INTRODUCTION}

In the last thirty years, the treatment for renal and ureteral calculi has undergone profound variations, because of the development of extracorporeal lithotripsy, followed by the improvement of endourological instruments which have allowed to access the excretory cavities in a retrograde manner and have proved to be safe and effective (1-10). The "mini-invasive" therapies have even changed treatment indications of small sized stones, which apparently could be expelled spontaneously $(11,12)$.

In fact, a patient affected by renal/ureteral calculi is not always likely to undergo a spontaneous expulsion, which could be achieved by means of relapsing colic that would require frequent administration of analgesic and antispasmodic drugs, and often lead to the need of accessing emergency rooms. Thus, the requirement on behalf of the patient is an immediate remedy and above all, a resolving one. After all, a long wait in the case of an urinary tract obstruction can damage the renal function thus, an immediate remedy is highly important $(13,14)$. The objective of this study has been to evaluate the existence of parameters which can affect the spontaneous expulsion of a symptomatic ureteral stone in a reasonably brief period of time so as not to damage the renal function and not to create an excessive discomfort in the patient due to the relapse of the symptoms. Another objective has been to identify whether certain parameters such as sex, age, the location and dimension of the stone, the presence of dilation in the urinary tract together with the administered therapy, can be used for a correct clinical management of the patient. In the case of favorable parameters, to then consider whether reasonable, keeping the subject under observation while waiting for a spontaneous expulsion, or otherwise, to perform an immediate treatment or to defer it in a short time span.

\section{MATERIALS AND METHODS}

In this observational study, emergency patients for renal colic were taken into consideration and then, only those in who a ureteral calculus was documentable at the moment of the imaging investigations, were evaluated, complete of an abdominal-pelvic ultrasonography (US), kidney, ureter, and bladder plain x-ray (KUB), and in some cases, a computerized tomography (CT). In a period of 9 months, 486 cases of renal colic were registered at emergency department out of a total 41,796 accesses to the same (1.2\%). The cases of renal colic due to ureteral calculus were 188 (38.7\%). Of each patient, the following aspects were evaluated: sex, age, the date of access to the emergency room, the emergency examinations carried out, the side of the stone, the location in the ureter, the dimension of the calculus (major and minor diameter), the radio-opacity, the presence of dilation in the urinary tract, the administered therapy, the results of the specialist's examinations together with the treatment carried out. Patients who required hospitalization, because presenting a concomitant, clinical situation such as urosepsis, acute

No conflict of interest declared. 
renal failure and documented, perirenal fluid collection, were excluded. In patients who went through spontaneous expulsion, the same investigations that lead to the diagnosis were prescribed, so as to verify the complete expulsion and, analogously, for the treated patients, so as to confirm the therapy result. The patients' charts, complete of all data and therefore, valid for this research, resulted to be 120 (64\%). The data was inserted in a database created by means of Excel. The non parametric values were considered in terms of the average \pm standard deviation (SD) and the median one with an interquartile range (I.R.). The statistical analysis was carried out by means of SPSS software (Statistical Package for Social Sciences, version 12.0) using the T-Student test in order to compare the average age between males and females, the Mann-Whitney test as to confront the major and minor diameter of the calculi, stratified on the basis of colic resolution and on the spontaneous expulsion, together with the Chi-squared test for the comparison of the categorical variables taken into consideration. A value of $p<0.05$ was considered significant (two-tailed test).

\section{RESULTS}

Table 1 relates the general characteristics of the population. As concerns the characteristics of the calculi (Table 2), no significant difference was found regarding the side $(46.7 \%$ on the right and $53.3 \%$ on the left). In 8 cases, the calculus was localized at the pelvis or at the ureteropelvic junction, in 42 cases (35\%), at the proximal ureter, in $36(30 \%)$, at the mid ureter, in $13(10.8 \%)$, at the distal ureter and in 21 (17.5\%), at the terminal ureter. The average sizes were of $6.5 \mathrm{~mm}$ (range 115) as regards the major diameter and of $4.3 \mathrm{~mm}$ (range 1-10) as regards the minor one. $85.8 \%(103 / 120)$ of the calculi turned out to be radiopaque, while $8.4 \%$ (10/120) were poor radiopaque and 5.8\% (7/120) were completely radiolucent.
Table 2

Characteristics of the stones.

\begin{tabular}{|c|c|}
\hline Laterality of stone $\mathrm{n}^{\circ}(\%)$ & 120 \\
\hline - Right & $56(46.7 \%)$ \\
\hline - Left & $64(53.3 \%)$ \\
\hline \multicolumn{2}{|l|}{ Location of stone $\mathrm{n}^{\circ}(\%)$} \\
\hline - Renal pelvis & $3(2.5 \%)$ \\
\hline - Ureteropelvic junction & $5(4.2 \%)$ \\
\hline - Proximal ureter & 42 (35\%) \\
\hline - Mid ureter & $36(30 \%)$ \\
\hline - Distal ureter & $13(10.8 \%)$ \\
\hline - Terminal ureter & $21(17.5 \%)$ \\
\hline \multicolumn{2}{|c|}{ Stone size mean $\mathbf{m m}$ (range) } \\
\hline - Major diameter & $6.5(1-15)$ \\
\hline - Minor diameter & $4.3(1-10)$ \\
\hline \multicolumn{2}{|l|}{ Radiopacity $\mathbf{n}^{\circ}$ (range) } \\
\hline - Radiopaque & $103(85.5 \%)$ \\
\hline - Poor radiopaque & $10(8.4 \%)$ \\
\hline - Radiolucent & $7(5.7 \%)$ \\
\hline
\end{tabular}

In $65.8 \%$ (79/120) of cases, dilation of the upper urinary tract was present

Patients were treated with a single drug in $67.5 \%$ of cases (81/120) thus resolving the pain symptoms. In $32.5 \%$ (39/120) of cases, multiple drugs were administered. In 18 cases (15\%), the symptoms could not be resolved,

\section{Table 1.}

Demographics.

\begin{tabular}{|lc|}
\hline $\mathbf{N}^{\circ}$ of patients (\%) & 120 \\
$\cdot$ Male & $88(73.3 \%)$ \\
$\cdot$ Female & $31(26.6 \%)$ \\
\hline Mean age years (range) & $46.6(21-85)$ \\
$\cdot$ Male & $47.2(24-85)$ \\
$\cdot$ Female & $45.2(21-77)$ \\
\hline Colics $\mathbf{n}^{\circ}(\%)$ & \\
$\cdot$ First episode & $55(45.8 \%)$ \\
$\cdot$ Recurrence & $65(54.2 \%)$ \\
\hline Imaging $\mathbf{n}^{\circ}(\%)$ & \\
$\cdot$ KUB + US & $104(86.7 \%)$ \\
$\cdot$ US & $10(8.3 \%)$ \\
- CT & $6(5 \%)$ \\
\hline
\end{tabular}

Figure 1.

Comparison between major (a) and minor (b) diameter (mean $\mathrm{mm}$ ) of stones and outcome of renal colic (Mann Whitney test: $p=N S$ ).

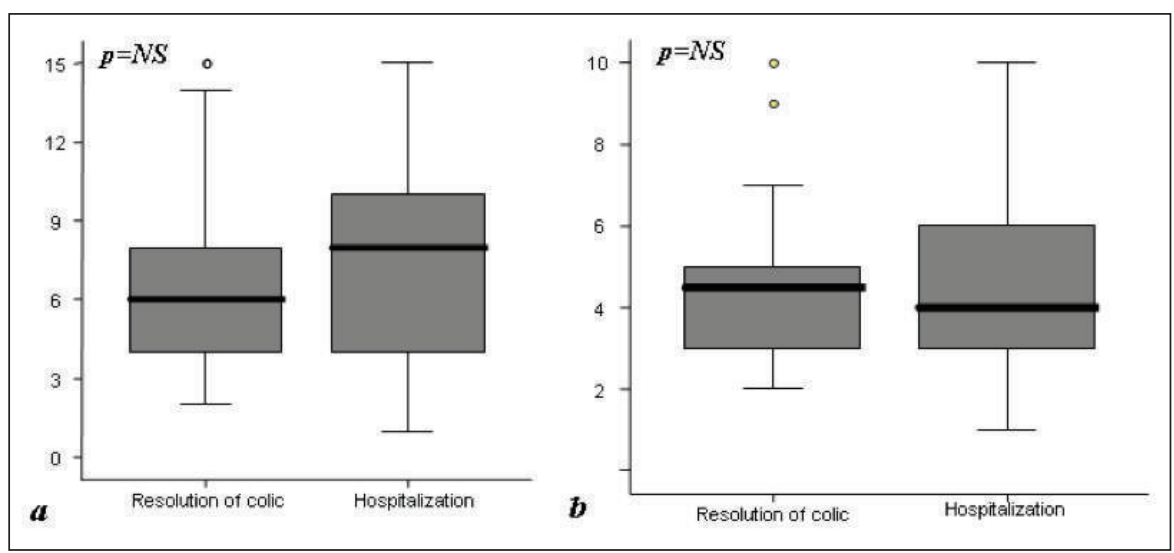

which lead to necessary hospitalization, while 102 patients were released from the hospital thanks to a pharmacologic treatment based on the administration of analgesics together with anti-inflammatory drugs, and in $40.2 \%$ of cases (41/102), an alpha-blocker was added. The statistical analysis was carried out on 119 patients instead of 120 due to one case of pregnancy, which required a different treatment compared to the traditionally used ones.

From the analysis of the data, no significant differences came out between the dimensions of the calculus and the result of the colic, thus confirming the impression that the pain symptoms are independent from the size of the calculus (Mann Whitney test: $\mathrm{p}=\mathrm{NS}$ ) (Figure 1). No significant statistical differences were noted neither between the 
location of the calculus and the relief from the pain symptoms, nor between the presence of hydroureteronephrosis and the relief from the pain symptoms (chi-square test: $p$ = NS) (Tables 3, 4).

However, a statistically significant difference did appear between the emergency symptomatic treatment carried out and the breakdown of the colic (chi-square test: $p \leq 0.01$ ). As a matter of fact, the patients who responded quickly to the administration of a single drug had a stronger possibility of long-lasting pain relief and fewer possibilities of hospitalization when compared to those who had undergone a multiple, pharmacological therapy (Table 5). During the period of this research, 60.8\% (73/120) of patients had spontaneously expelled the calculus responsible for the colic, in a time period ranging up to 4 weeks.

In 14 cases (11.7\%), emergency treatment with retrograde ureteroscopy (URS) was carried out with a complete resolution in all cases. For other 33 patients (27.5\%), a deferred treatment was planned and then carried out: in 12 cases extracorporeal lithotripsy (SWL) was done and its outcomes proved to resolve 10 cases (83.3\%), while in other 21 cases, lithotripsy by ureteroscopy cured all cases (100\%) (Table 6).

Regarding the possibilities of spontaneous expulsion on

\section{Table 3.}

Comparison between location of the stone and resolution of colic (chi-square test: $p=0.147-N S$ ).

\begin{tabular}{|llccc|}
\hline & \multicolumn{3}{c|}{ Resolution of colic } & Total \\
\hline Location & Yes & Hospitalization & \\
& Pelvis & 2 & 1 & 3 \\
& UPJ & 3 & 2 & 5 \\
& Proximal & 36 & 6 & 42 \\
& Mid & 34 & 2 & 36 \\
& Lower & 12 & 1 & 13 \\
& Terminal & 15 & 5 & 20 \\
\hline Total & & 102 & 17 & 119 \\
\hline
\end{tabular}

Table 4.

Comparison between hydroureteronephrosis and resolution of colic (chi-square test: $p=0.692-N S$ ).

\begin{tabular}{|c|c|c|c|}
\hline \multirow[t]{2}{*}{ Hydroureteronephrosis } & \multicolumn{2}{|c|}{ Resolution of colic } & \multirow[t]{2}{*}{ Total } \\
\hline & Yes & Hospitalization & \\
\hline Absent & 35 & 5 & 40 \\
\hline Present & 67 & 12 & 79 \\
\hline Total & 102 & 17 & 119 \\
\hline
\end{tabular}

Table 5.

Comparison between medical therapy and resolution of colic (chi-square test: ${ }^{\star} p=0.007$ ).

\begin{tabular}{|c|c|c|c|c|}
\hline \multicolumn{2}{|c|}{ Medical therapy } & \multicolumn{2}{|c|}{ Resolution of colic } & \multirow{2}{*}{$\frac{\text { Total }}{5}$} \\
\hline & Diclofenac & 5 & 0 & \\
\hline & Ketorolac & 49 & 4 & 53 \\
\hline & Other NSAID & 17 & 1 & 18 \\
\hline & Antispasmodics & 5 & 0 & 5 \\
\hline & Multiple drugs * & 26 & 12 & 38 \\
\hline Total & & 102 & 17 & 119 \\
\hline
\end{tabular}

Table 6.

Outcome of colics.

\begin{tabular}{|lcc|}
\hline & $\mathbf{N}^{\circ}(\%)$ & Resolution $\mathbf{n}^{\circ}(\%)$ \\
\hline Spontaneous stone expulsion & $73(60.8 \%)$ & \\
\hline Immediate treatment (URS) & $14(11.7 \%)$ & $14(100 \%)$ \\
\hline Elective treatment & $33(27.5 \%)$ & \\
$\cdot$ ESWL & 12 & $10(83.5 \%)$ \\
- URS & 21 & $21(100 \%)$ \\
\hline
\end{tabular}

Table 7.

Comparison between spontaneous stone expulsion and location of stones (Chi-Square Test: $p=0.128-N S$ ).

\begin{tabular}{|llccc|}
\hline & \multicolumn{2}{c}{ Stone expulsion } & Total \\
\hline Location & Pelvis & 1 & NO & \\
& UPJ & 1 & 2 & 3 \\
& Proximal & 23 & 19 & 5 \\
& Mid & 25 & 11 & 32 \\
& Distal & 7 & 6 & 13 \\
& Terminal & 16 & 5 & 21 \\
\hline Total & & 73 & 47 & 120 \\
\hline
\end{tabular}

Table 8.

Comparison between spontaneous stone expulsion and hydroureteronephrosis (Chi-Square Test: $p=0.444$ - NS).

\begin{tabular}{|c|c|c|c|}
\hline \multirow{2}{*}{ Hydroureteronephrosis } & \multicolumn{2}{|c|}{ Stone expulsion } & \multirow{2}{*}{ Total } \\
\hline & YES & NO & \\
\hline Absent & 23 & 18 & 41 \\
\hline Present & 50 & 29 & 79 \\
\hline$\overline{\text { Total }}$ & 73 & 47 & 120 \\
\hline
\end{tabular}

Table 9.

Comparison between spontaneous stone expulsion of stones and home therapy (Chi-Square Test: $p=0.515$ - NS).

\begin{tabular}{|c|c|c|c|}
\hline \multirow[t]{2}{*}{ Home therapy } & \multicolumn{2}{|r|}{ Stone expulsion } & \multirow[t]{2}{*}{ Total } \\
\hline & YES & NO & \\
\hline Flavoxate & 9 & 8 & 17 \\
\hline Other antispasmodics & 1 & 1 & 2 \\
\hline$\alpha$-blockers & 7 & 7 & 14 \\
\hline NSAID & 35 & 24 & 59 \\
\hline Flavoxate $+\alpha$-blocker & 20 & 7 & 27 \\
\hline Total & 72 & 47 & 119 \\
\hline
\end{tabular}

the basis of sex, side and location of lithiasis (chi-square test; $p=$ NS) (Table 7), no relevant differences were observed. Not even the presence of hydroureteronephrosis seems to have any effect on the probabilities of spontaneous expulsion (chi-square test; $\mathrm{p}=$ NS) (Table 8). On the contrary of what has been reported in literature, in our casuistry, we were not able to statistically verify any significant differences between the various types of analgesic-antispasmodic treatments, which had been administered to the discharged patient, and the spontaneous expulsion of the calculus itself (chi-square test; $p=$ NS) (Table 9) (15-18). 
Table 10.

Comparison between spontaneous stone expulsion and stone composition (Ca-Ox: Calcium oxalate; $\mathrm{Ca}-\mathrm{Ox}+\mathrm{Ca}-\mathrm{P}$ : Calcium oxalate + Calcium phosphates; $\mathrm{Ca}-\mathrm{Ox}+\mathrm{UA}$ : Calcium oxalate + Uric acid; UA: Uric acid; NR: not reported) (Chi-Square Test: * $p=0.003$ ).

\begin{tabular}{|c|c|c|c|}
\hline \multirow[t]{2}{*}{ Stone composition } & \multicolumn{2}{|c|}{ Stone expulsion } & \multirow[t]{2}{*}{ Total } \\
\hline & YES & NO & \\
\hline Сa-0x & 7 & 16 & 23 \\
\hline $\mathrm{Ca}-0 \mathrm{x}+\mathrm{Ca}-\mathrm{P} *$ & 42 & 15 & 57 \\
\hline $\mathrm{Ca}-0 \mathrm{x}+\mathrm{UA}$ & 12 & 8 & 20 \\
\hline UA & 3 & 5 & 8 \\
\hline NR & 9 & 3 & 12 \\
\hline Total & 73 & 47 & 120 \\
\hline
\end{tabular}

We noticed that the only parameter which seemed to be statistically significant, was the one relative to the size of the calculus. It must be pointed out that both the major and minor diameter had a strong impact on the probability of spontaneous expulsion of the calculus (Figure 2). As concerns the chemical composition of the calculi, the statistical analysis underlined significant differences regarding the spontaneous expulsion between pure and mixed calculi (chi-square test; $\mathrm{p}<0.01$ ) (Table 10). In particular, spontaneous expulsion proved to be more probable for mixed calculi of oxalate and calcium phosphate when compared to pure calculi of calcium oxalate and of uric acid. However, we believe that this result cannot be sufficiently representative due to the reduced sample size, which did not allow the evaluation of other parameter, and that is, by stratifying it even on the basis of size of the stone. It is known, in fact, that uric acid calculi are susceptible to litholytic therapy by means of allopurinol and urine alkalinization. The use of these drugs often permits to reduce the size of the uric acid calculi to such a point as to allow them to undergo spontaneous expulsion and sometimes, even the complete dissolution $(19,20)$.

Figure 1.

Comparison between major (a) and minor (b) diameter (mean $\mathrm{mm}$ ) of stones and outcome of renal colic (Mann Whitney test: $p=N S$ ).

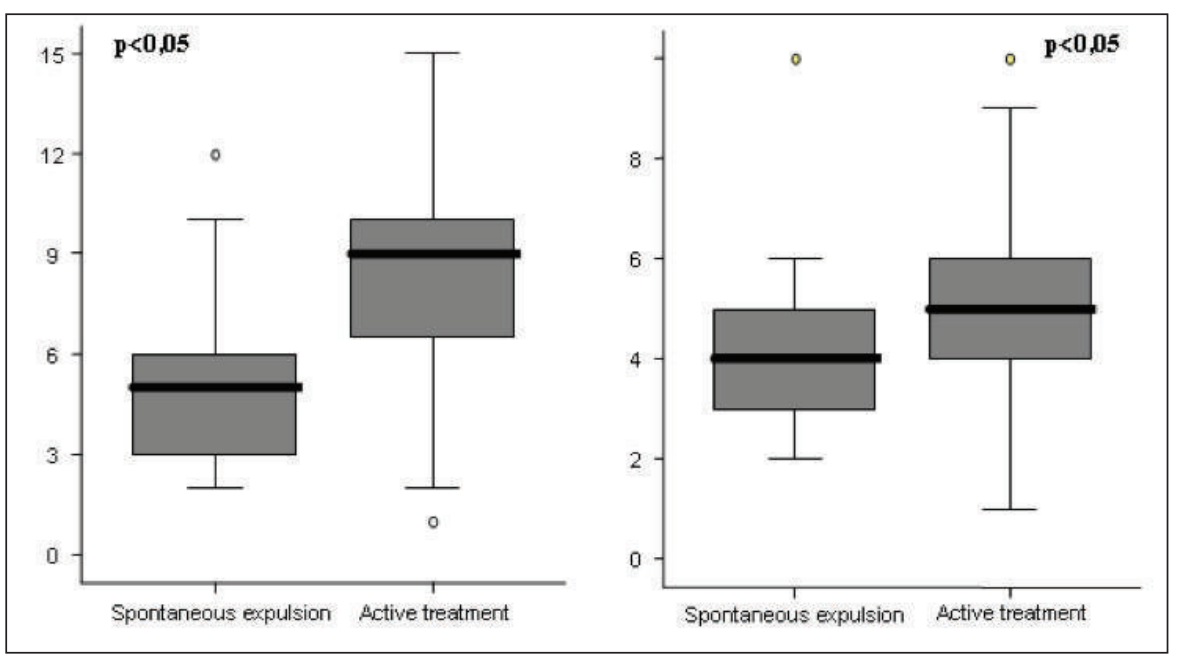

\section{Discussion}

Urinary calculi constitute a relatively frequent pathology and $5 \%$ of the population is affected. Renal colic represents the characteristic case history of the commitment of the stone as it goes down the urinary tract. As a matter of fact, it usually determines severe discomfort in the patient compelling the same to access the emergency room quite frequently. The lack of a clear and precise therapeutic plan may lead to further discomforts for the patient and furthermore, the increase of costs (21-23), considering that the risk of having renal colic, at least once in a lifetime, ranges between 8-15\% $(24,25)$.

Clear and precise guidelines regarding the management of a patient with renal colic do not exist. Concerning the diagnosis, several studies have reported that $\mathrm{CT}$ proves to be the method with the highest levels of sensitivity and specificity in the diagnostic procedures for renal colic. However, CT is not always possible in emergency situations therefore, in the majority of cases, the clinical diagnosis is frequently confirmed by means of a plain radiography of the abdomen, together with an abdominal ultrasonography, which are not always sufficient to correctly plan further procedures. On the other hand, the increase of CT use in patients with renal colic has not determined a corresponding, diagnostic increase of nephrolithiasis, which accounts for $20 \%$ of renal colic cases. Thus, it must be underlined that an extensive use of CT does increase the costs together with the risks related to radiological exposition (26).

Once established that the cause of renal colic is the presence of a ureteral calculus, a further procedure to follow must still be chosen. Dimension, location and form of a calculus have so far been considered as the determinant factors that mainly affect the decision relative to an active treatment of stones. The possibility of spontaneous expulsion, which occurs in $80 \%$ of cases for calculi with $<4 \mathrm{~mm}$ diameter, is reduced to $10 \%-53 \%$ in the presence of calculi ranging from $6-10 \mathrm{~mm}$. The diagnosis of a ureteral calculus of a $>7 \mathrm{~mm}$ diameter instead, suggest an active treatment $(27,28)$. Discharge of the patient with a prescription for an medical expulsive therapy is only possible in the case of complete resolution of the symptoms, if necessary with a prescription for an $\alpha$-blocker therapy in the cases of distal ureter calculi, although many authors sustain that the $\alpha$-blockers facilitates spontaneous expulsion above all (29-32). Forced hydration has proved not to be more effective than normal hydration and, on the contrary, it does not seem to affect spontaneous expulsion at all (33).

At the present, the therapeutic options regarding ureteral calculi include extracorporeal lithotripsy, ureteroscopic lithotripsy and surgical intervention meaning, laparoscopic ureterolithoto- 
my. Although, SWL seems to be less effective than other techniques, it is nevertheless, considered as first choice therapy for calculi found at the proximal ureter, while its role, in the cases of calculi in the mid and lower ureter, still remains controversial (34-36).

Ureteroscopic lithotripsy is carried out extensively in the treatment of ureteral calculi with an effectiveness that exceeds $90 \%$ and furthermore, with a low incidence of complications $(4,37)$; as concerns surgical intervention, whether it is traditional or carried out by means of the laparoscopic procedure, it currently represents a therapeutic option that can only be recommended in selected cases (38-40).

From the observational analysis about our series, regarding the spontaneous expulsion of the calculus, we can notice that the only valid and statistically relevant parameter proved to be the diameter of the calculus itself. Both the major and minor diameter play an important role, meaning that even calculi with a small, transverse diameter may be difficult to expel if their major diameter is big (for example, long and thin calculi). Other interesting data emerges from clinical cases where symptoms were resolved with the use of a single drug and no immediate hospitalization was needed. In these cases, if the patients had not spontaneously expelled the calculus in the following days after medical expulsive therapy, they would be treated with a planned elective treatment.

As regards the patients in whose symptoms could not be solved by means of the administration of analgesics, relapsing colic was frequent, to the point of requiring hospitalization and emergency treatment. The emergency treatment chosen and carried out by us, was always ureterorenoscopy. Although in literature, many studies have indicated extracorporeal lithotripsy as a possible and valid, urgency treatment, according to our experience, the limited results obtained by means of SWL, do not justify the use of such option in emergency cases. In fact, subjects who suffer of relapsing renal colic, do not accept that a less invasive treatment such as SWL, which actually ensures favorable results in only $60 \%$ of cases, could be associated with a further elevated incidence of colic during the expulsion of the fragments (41-44).

Thus, this study seems to confirm the validity of our choice treatment in the case of renal colic, meaning an immediate ureteroscopic lithotripsy when painful symptoms are present and cannot be solved by means of an analgesic-antispasmodic therapy. In patients in who the renal colic is solved, a wait of 4 weeks would be reasonable in order to safeguard the renal function. During these 4 weeks, it would thus be possible to plan for an elective treatment, if spontaneous expulsion of the calculus should not take place. The planned therapy, in these cases, could be an extracorporeal lithotripsy or an endourological one, according to the location and the dimension of the calculus together with the characteristics of the urinary tract.

\section{Conclusions}

To conclude, in the presence of a symptomatic ureteral stone, the correct approach must first of all, focalize on the dimension of the calculus itself; less importance instead, should be given to the location, as reported in other studies, presence of hydroureteronephrosis, sex and the side. In the cases when the pain symptoms cannot be solved by means of the administration of analgesics, it is then reasonable to take into consideration an immediate endourological treatment, in relation to the choice of patient. If the pain symptoms are promptly solved, an attentive wait of 4 weeks should be considered reasonable in order to allow spontaneous expulsion of the calculus, hence, without excessively compromising the renal function and/or to program an elective treatment with of an endourological approach or of extracorporeal lithotripsy.

\section{ACKNOWLEDGements}

Sincerely thanks to Prof. Dunya Bernardon for grammatical editing of the manuscript.

\section{References}

1. Chaussy C, Schmiedt E, Jocham D, et al. First clinical experience with extracorporeally induced destruction of kidney stones by shock waves. J Urol. 1982; 127:417-420.

2. Rassweiler JJ, Renner C, Chaussy C, Thüroff S. Treatment of renal stones by extracorporeal shockwave lithotripsy: an update. Eur Urol. 2001; 39:187-199.

3. Galvin DJ, Pearle MS. The contemporary management of renal and ureteric calculi. BJU Int. 2006; 98:1283-1288.

4. Preminger GM, Tiselius HG, Assimos DG, et al. American Urological Association Education and Research, Inc; European Association of Urology. 2007 Guideline for the management of ureteral calculi. Eur Urol. 2007; 52:1610-1631.

5. Miller NL, Lingeman JE. Management of kidney stones. BMJ 2007;334:468-472.

6. Zanetti G, Trinchieri A, Montanari E, Rocco F. SWL.our twentyfour year experience. Arch Ital Urol Androl. 2008; 80:21-26.

7. Babayan RK, Wang DS. Optics of Flexible and Rigid Endoscopes: Physical Principals; in: Smith AD, Badlani GH, Bagley DH, et al. Smith's Textbook of Endourology. London, BC Decker Inc, 2006, pp 3-5.

8. Lahme S, Zimmermanns V, Hochmuth A, Liske P. Stones of the upper urinary tract. Update on minimal-invasive endourological treatment. Arch Ital Urol Androl. 2008; 80:13-17.

9. Wignall GR, Canales BK, Denstedt JD, Monga M. Minimally invasive approaches to upper urinary tract urolithiasis. Urol Clin North Am. 2008; 35:441-454.

10. Eisner BH, Kurtz MP, Dretler SP. Ureteroscopy for the management of stone disease. Nat Rev Urol. 2010; 7:40-45.

11. Miller OF, Kane CJ. Time to stone passage for observed ureteral calculi: a guide for patient education. J Urol. 1999; 162:688-690.

12. Coll DM, Varanelli MJ, Smith RC. Relationship of spontaneous passage of ureteral calculi to stone size and location as revealed by unenhanced helical CT. AJR Am J Roentgenol. 2002; 178:101-103.

13. Shapiro SR, Bennett AH. Recovery of renal function after prolonged unilateral ureteral obstruction. J Urol. 1976; 115:136-140.

14. Truong LD, Gaber L, Eknoyan G. Obstructive uropathy. Contrib Nephrol. 2011; 169:311-326. 
15. Singh A, Alter HJ, Littlepage A. A systematic review of medical therapy to facilitate passage of ureteral calculi. Ann Emerg Med. 2007; 50:552-563.

16. Pedro RN, Hinck B, Hendlin K, et al. Alfuzosin stone expulsion therapy for distal ureteral calculi: a double-blind, placebo controlled study. J Urol. 2008; 179:2244-2247.

17. Ferre RM, Wasielewski JN, Strout TD, Perron AD. Tamsulosin for ureteral stones in the emergency department: a randomized, controlled trial. Ann Emerg Med. 2009; 54:432-439.

18. Sun X, He L, Ge W, Lv J. Efficacy of selective alphalD-blocker naftopidil as medical expulsive therapy for distal ureteral stones. $J$ Urol. 2009; 181:1716-1720.

19. Sterrett SP, Penniston KL, Wolf JS Jr, Nakada SY. Acetazolamide is an effective adjunct for urinary alkalization in patients with uric acid and cystine stone formation recalcitrant to potassium citrate. Urology. 2008; 72:278-281.

20. Trinchieri A, Esposito N, Castelnuovo C. Dissolution of radiolucent renal stones by oral alkalinization with potassium citrate/potassium bicarbonate. Arch Ital Urol Androl. 2009; 81:188-191.

21. Phillips E, Kieley S, Johnson EB, Monga M. Emergency room management of ureteral calculi: current practices. J Endourol. 2009; 23:1021-1024.

22. Sterrett SP, Moore NW, Nakada SY. Emergency room follow-up trends in urolithiasis: single-center report. Urology. 2009; 73:11951197.

23. Turkcuer I, Serinken M, Karcioglu O, et al. Hospital cost analysis of management of patients with renal colic in the emergency department. Urol Res. 2010; 38:29-33.

24. Tiselius HG. Epidemiology and medical management of stone disease. BJU Int. 2003; 91:758-767.

25. Amato M, Lusini ML, Nelli F. Epidemiology of nephrolithiasis today. Urol Int. 2004; 72:1-5.

26. Hyams ES, Korley FK, Pham JC, Matlaga BR. Trends in imaging use during the emergency department evaluation of flank pain. J Urol. 2011; 186:2270-2274.

27. Sandegard E. Prognosis of stone in the ureter. Acta Chir Scand Suppl. 1956; 219:1-67.

28. Masarani M, Dinneen M. Ureteric colic: new trends in diagnosis and treatment. Postgrad Med J. 2007; 83:469-472.

29. Yilmaz E, Batislam E, Basar MM, et al. The comparison and efficacy of 3 different alphal-adrenergic blockers for distal ureteral stones. J Urol. 2005; 173:2010-2012.

30. Hollingsworth JM, Rogers MA, Kaufman SR, et al Medical ther- apy to facilitate urinary stone passage: a meta-analysis. Lancet. 2006; 368:1171-1179.

31. Beach MA, Mauro LS. Pharmacologic expulsive treatment of ureteral calculi. Ann Pharmacother. 2006; 40:1361-1368.

32. Sterrett SP, Nakada SY. Medical expulsive therapy. Curr Opin Urol. 2008; 18:210-213.

33. Springhart WP, Marguet CG, Sur RL, et al. Forced versus minimal intravenous hydration in the management of acute renal colic: a randomized trial. J Endourol. 2006; 20:713-716.

34. Lam JS, Greene TD, Gupta M. Treatment of proximal ureteral calculi: Holmium:YAG laser ureterolithotripsy versus extracorporeal shock wave lithotripsy. J Urol. 2002; 167:1972-1976.

35. Ziaee SA, Basiri A, Nadjafi-Semnani M, et al. Extracorporeal shock wave lithotripsy and transureteral lithotripsy in the treatment of impacted lower ureteral calculi. Urol J. 2006; 3:75-78.

36. Kijvikai K, Haleblian GE, Preminger GM, de la Rosette J. Shock wave lithotripsy or ureteroscopy for the management of proximal ureteral calculi: an old discussion revisited. J Urol. 2007; 178:11571163.

37. Zattoni F. Ureteroscopy. Complications. In: Smith AD et al (ed): Smith's Textbook of Endourology, London, BC Decker Inc, 2006. Chapter 36, pp 295-303.

38. Kane CJ, Bolton DM, Stoller ML. Current indications for open stone surgery in an endourological centre. Urology. 1995; 45:218-221.

39. Gaur DD, Trivedi S, Prabhudesai MR, Madhusudhana HR, Gopichand M. Laparoscopic ureterolithotomy: technical considerations and long term follow up. BJU Int. 2002; 89:339-343.

40. Kijvikai K, Patcharatrakul S. Laparoscopic ureterolithotomy: its role and some controversial technical considerations. Int J Urol. 2006; 13:206-210.

41. Ghoneim IA, El-Ghoneimy MN, El-Naggar AE, et al. Extracorporeal Shock Wave Lithotripsy in Impacted Upper Ureteral Stones: A Prospective Randomized Comparison Between Stented and Non-stented Techniques. Urology. 2010; 75:45-50.

42. Argyropoulos AN, Tolley DA. Failure after shockwave lithotripsy: is outcome machine dependent? Int J Clin Pract. 2009; 63:14891493.

43. Guercio S, Ambu A, Mangione F, et al. Randomized prospective trial comparing immediate versus delayed ureteroscopy for patients with ureteral calculi and normal renal function who present to the emergency department. J Endourol. 2011; 25:1137-1141.

44. Yang S, Qian H, Song C, et al. Emergency ureteroscopic treatment for upper urinary tract calculi obstruction associated with acute renal failure: feasible or not? J Endourol. 2010; 24:1721-1724.

\section{Correspondence}

Paolo Beltrami, MD

paolo.beltrami@sanita.padova.it

Andrea Guttilla, MD

Filiberto Zattoni, MD

Endourology Unit, Urology Clinic, Department of Surgical Oncological and Gastroenterological Sciences, University of Padua

Via Giustiniani, 2 - 35128 Padova, Italy

Lorenzo Ruggera, MD

Department of Urology, S. Maria degli Angeli Hospital, Pordenone, Italy

Patrizia Bernich, MD

Department of Nephrology, University of Verona, Verona, Italy 